\title{
Las dinámicas del voto retrospectivo en España (1996-2017)
}

\author{
Antonio Alaminos \\ Paloma Alaminos-Fernández \\ Universidad de Alicante, Alicante, España
}

\begin{abstract}
Resumen ${ }^{1}$ : Tras introducir brevemente algunos conceptos explicativos del voto desde el punto de vista de su influencia a largo, medio y corto plazo, se efectúa un análisis desde el enfoque del modelo de voto retrospectivo. Se analizan cuatro series del banco de datos del Centro de Investigaciones Sociológicas, con la valoración de la gestión/actuación del Partido Popular y del Partido Socialista Obrero Español, así como las series de intención de voto a los dos partidos. Del análisis se concluye la estrecha relación existente entre la valoración de la gestión/ actuación de ambos partidos con su intención de voto. Las tendencias de declive observadas en la confianza en la gestión/actuación de los dos partidos anticipaban el escenario de crisis del bipartidismo de 2015, sugiriendo su incorporación como elemento de su «imagen de partido». Así mismo, considerando las dinámicas para los dos partidos, se observa la anomalía que, dentro de la pauta general, representan las elecciones generales de 2004 y 2011. Como estrategia de control de la falacia ecológica de los agregados, se ha efectuado un control en cinco años (1997, 2002, 2007, 2012 y 2017) analizando los microdatos para establecer la relación entre valoración de la gestión/actuación del partido y su intención de voto en la unidad de análisis individual.
\end{abstract}

Palabras clave: cambio político, tendencias, voto retrospectivo, Partido Popular, Partido Socialista Obrero Español

Abstract: After briefly introducing some of the explanatory concepts of voting from the point of view of its influence in the long, medium and short term, an analysis is made from the retrospective voting model approach. For the Spanish case, four series of the Centre for Sociological Research database are analysed, with the assessment of the management/performance of the Popular Party and the

${ }^{1}$ La investigación fue efectuada durante una estancia de investigación en 2017 del profesor Antonio Alaminos en el GESIS - Leibniz-Institute for the Social Sciences, financiada con la ayuda PRX16/00176, del programa de movilidad Salvador de Madariaga del Ministerio de Educación, Cultura y Deporte. 
Spanish Socialist Workers' Party, as well as the series of voting intention to the two political parties. The analysis concludes the close relationship between the assessment of the management/performance of both political parties with their voting intention. The trends of decline observed in the trust in management/performance of the two parties anticipated the bipartisan crisis scenario of 2015. Furthermore, considering the dynamics for the two parties, we observe the anomaly that, within the general pattern, represents the general elections of 2004 and 2011. As a strategy to control the ecological fallacy of the aggregates, an analysis has been carried out in five years $(1997,2002,2007,2012$ and 2017) studying the microdata to establish the relationship between management/performance valuation of the party and the voting intention at an individual level.

Keywords: political change, trends, retrospective voting, Partido Popular, Partido Socialista Obrero Español 


\section{INTRODUCCIÓN}

Las series temporales han sido utilizadas profusamente en la investigación del votante, empleando múltiples variables como factores explicativos del voto. Los modelos basados en series temporales tienen una amplia tradición en el mundo anglosajón, con antecedentes evidentes en Lewis-Beck y Rice (1992) o Campbell y Garand (2000). Cuando se realiza el estudio de los comportamientos electorales desde el enfoque de las series temporales se parte de la premisa de que en los resultados electorales de un partido político y, en definitiva, en los procesos de decisión de un votante influyen factores que actúan a corto, medio y largo plazo. La imagen del proceso aporta contexto y perspectiva en la interpretación de lo observado en un momento puntual.

En ese sentido, el estudio de estructuras de opinión y su evolución mediante encuestas sucesivas de opinión pública (raramente mediante panel) ofrece una imagen demasiado coyuntural de los procesos electorales. El investigador analiza el último estado de un proceso, considerando el pasado casi de forma exclusiva para los modelos de estimación de voto o ejercicios de prospectiva. Así, la estimación o incluso la intención de voto se interpreta a través de los medios de comunicación como una sucesión de fotos de un fenómeno social en movimiento. Esta aproximación empírica mediante una sucesión de fotos estáticas es bastante limitada en lo que se refiere a la comprensión de los procesos y dinámicas del cambio social.

Ello no devalúa el importante significado de las encuestas de opinión como mediciones del estado del proceso. Son muchos los estudios que señalan la capacidad de las encuestas preelectorales para afinar los resultados dentro del intervalo que señalan las tendencias. Esta información de última hora permite corregir las estimaciones incrementando su fiabilidad y precisión. Según varios estudios, las encuestas próximas a las elecciones (como media tres meses antes de ellas) facilitan los datos más fiables para una predicción electoral (Traugott, 2001, 2005; Pickup y Johnston, 2008; Panagopoulos, 2009c; Alaminos, 1994). Cuanto más antiguos son los datos, la precisión disminuye (Campbell y Wink, 1990; Gelman y King, 1993; Campbell, 1996), siendo útiles para evaluar las tendencias observadas, pero contribuyendo en menor grado al estado actual. La comparación entre ambos métodos para establecer una mejor o peor capacidad predictiva (encuestas próximas a las elecciones o series temporales) ha establecido la importancia de la complementariedad entre ellas (Brown y Chappell, 1999).

Desde una perspectiva longitudinal, los efectos a corto, medio y largo plazo deben ser tenidos en cuenta analíticamente para explicar la situación electoral actual (diferenciando entre tendencia y coyuntura), así como la previsión de las dinámicas futuras. Vamos a introducir de manera breve algunos conceptos teóricos explicativos del voto 
desde la óptica de su contribución temporal. En primer lugar, los elementos que tienen un efecto de largo plazo aportan memoria a la serie; a medio plazo, se espera que su efecto tenga una duración temporal menor y cambie con algún evento de referencia, como puede ser un cambio de Gobierno. A corto plazo, producen impactos de última hora en las dinámicas de voto.

El efecto en los resultados electorales de los votantes militantes son un claro ejemplo de factor de largo plazo, como han mostrado empíricamente diversos autores, y en especial para el caso de las elecciones norteamericanas (Campbell et al., 1960; Lewis Beck et al., 2008) o alemanas (Falter y Rattinger, 1982; Norpoth, 1978). En el caso español, y para cada ciclo electoral, han determinado un suelo electoral de referencia para cada partido esencial en cualquier ejercicio de prospectiva electoral (Alaminos, 1996). Para la estimación de este voto militante de los partidos pueden emplearse varias aproximaciones, usando tanto encuestas como los resultados efectivos obtenidos en varias convocatorias electorales (Tufte, 1978). En este segundo caso, la estabilidad del apoyo electoral se expresa de forma diáfana en los resultados, ya sea en la forma de un mínimo de referencia o mediante estimaciones de apoyo medio. Sin embargo, es importante considerar la amplitud del periodo de tiempo considerado, así como la presencia de ciclos electorales, en la medida que el suelo electoral de un partido puede fluctuar. La noción de ciclo electoral está presente en la idea de efecto a largo plazo, en la medida que las dinámicas de reemplazo generacional terminan modificando la estructura del voto militante.

La identificación partidaria, tanto a nivel individual como agregada, es una aproximación alternativa a la estabilidad del voto militante. Como hemos considerado, es factible establecer un suelo en el apoyo electoral de un partido político a partir de sus resultados electorales sucesivos. Asimismo, este elemento de estabilidad en el largo plazo puede establecerse mediante la identificación que los individuos afirman mantener con los partidos. Norpoth (2010) propone que la distribución del porcentaje agregado de identificación con partidos políticos puede ser considerada como una referencia mínima para el resultado electoral de unas elecciones realizadas en condiciones normales.

El concepto de «identificación partidaria» fue formulado originariamente desde la psicología social (Belknap y Campbell, 1952; Campbell, Gurin y Miller, 1954; Campbell et al., 1960, 1966) y se define como «la orientación afectiva que un individuo mantiene con un grupo-objeto importante en su entorno» (Campbell et al., 1960:121). Es evidente que de la definición no se desprende la idea de que esta afinidad con los partidos deba ser estable en el tiempo. Sin embargo, estos autores establecieron que para el electorado norteamericano la estabilidad en la identificación partidaria era la norma. 
Solo en periodos excepcionales de realineamiento se podían apreciar cambios en esa fijación afectiva. El argumento que respaldaba teóricamente esa observación de estabilidad plantea que la identificación con un partido se establece en las etapas de socialización temprana, de tal modo que el trascurso del tiempo actúa reforzando dicha identificación (Campbell et al., 1960; Converse, 1969, 1976; Jennings y Niemi, 1974). Evidentemente, tanto la definición de identificación como la afirmación sobre su estabilidad en el tiempo ha sido desde el inicio objeto de análisis y debate.

Así, en lo referido a la definición, son varios los autores que partiendo de los trabajos de Downs (1957) o Key (1968) proponen que los procesos psicológicos que generan la identificación partidaria son de tipo cognitivo y evaluativo (y no afectivo). La consecuencia de redefinir el concepto es que, por ejemplo, para Fiorina (1981) la «identificación partidista» es el resumen de las evaluaciones presentes y pasadas de la actuación del partido. Desde esta definición, la identificación partidista es un proceso dinámico que se modifica dependiendo de la información que recibe el votante sobre los partidos. Por ello, la identificación partidaria, en esta interpretación cognitiva y evaluativa (Achen, 1992; Erikson, MacKuen y Stimson, 2002; Fiorina, 1981; Franklin, 1984; Franklin y Jackson, 1983; MacKuen, Erikson y Stimson, 1989), es dinámica y cambia en el tiempo según las circunstancias. En esta interpretación, la identificación con partidos tendría un efecto más reducido en los análisis de largo recorrido temporal, al ser dependiente de la actuación del partido. Esta redefinición del concepto prescinde del atributo de estabilidad (v.g., Alt, 1984; Clarke et al., 2004; Clarke, Stewart y Whiteley, 1997a, 1997b; Stewart y Clarke, 1998) y permitiría explicar la volatilidad que se aprecia en su medición mediante paneles o los grandes vuelcos electorales observados.

Sin embargo, en el caso de la variabilidad medida mediante panel, la estabilidad en la identificación partidaria es bastante elevada para el caso de los países anglosajones, cuando se emplean variables latentes (Green, Palmquist y Schickler, 2002; Schickler y Green, 1997). En ese sentido, queda aún por resolver, desde el punto de vista empírico, hasta qué punto la inestabilidad o estabilidad observada en la identificación partidaria es dependiente del método de análisis empleado.

En el debate sobre la estabilidad individual o agregada en la identificación de partido, la posición alternativa defiende la estabilidad. Así, Dalton (2016:1) destaca que «la identificación con partidos es una identificación psicológica establecida con un partido político en las primeras etapas de socialización, afectiva y de carácter duradero». Dalton adopta la interpretación afectiva de la identificación. Este carácter afectivo (a diferencia de la caracterización evaluativa o cognitiva) aporta estabilidad a la identificación partidaria como variable explicativa, y es precisamente en su permanencia donde se encuentra para ellos la importancia especial de esta variable. La identificación con partidos 
estructuraría la forma en que los individuos perciben la política, condicionando la valoración de los candidatos o la defensa de unos temas sobre otros, orientando la intención de voto y la decisión de participar en las elecciones. Esta identificación afectiva, según Russel, promueve la estabilidad del sistema electoral. La identificación con partidos políticos ha sido y es un objeto de estudio significativo al considerar los efectos de largo plazo en una tendencia electoral. En especial, en aquellos casos donde la estabilidad en la identificación es elevada a lo largo del tiempo. Así, en el caso de definir la «identificación partidaria» por sus rasgos afectivos, se trataría de un efecto de largo plazo. En su versión cognitiva o evaluativa, esta identificación correspondería con un efecto a medio plazo, propia de los enfoques del voto retrospectivo.

Por otra parte, también se ha debatido la utilidad práctica de exportar a otros países la noción de identificación partidaria (Budge, Crewe y Farlie, 1976; Fleury y LewisBeck, 1993; Scarbrough, 1984). Para estos autores, la estabilidad de la identificación partidaria es una cualidad específica del sistema electoral y del sistema de partidos e institucional de los Estados Unidos, y no de su propiedad afectiva o cognitiva. Así, en su empleo como factor explicativo del voto en otros países, la identificación partidaria sería redundante con otras cleavages políticas o variables sociodemográficas más estables y, por lo tanto, prescindible como elemento explicativo.

Otro concepto relacionado con el anterior, si bien con contenidos diferenciados, es el de «imagen de partido». La imagen de partido es un factor que puede considerarse de largo plazo, en la medida que su valor es usualmente de difícil o lenta modificación. La imagen de partido, aunque tiene una relación importante con la imagen del líder de dicho partido, puede considerarse un «objeto político»² (Almond y Verba, 1965; Easton, 1975) diferenciado, que forma parte de la cultura política de un país. Si Almond y Verba definían cultura política como «una distribución particular de pautas de orientación hacia objetos políticos entre los miembros de una nación» (Almond y Verba, 1965:13), Easton definía la noción de «apoyo político» como «una actitud por la que una persona se orienta a sí misma hacia un objeto de forma favorable o desfavorable, positiva o negativa» (Easton, 1975:436). La imagen de partido viene a formar parte de los objetos políticos hacia los que se expresa el apoyo político.

${ }^{2}$ Almond y Verba (1965), además de distinguir entre diferentes «objetos políticos», y siguiendo a Parsons y Shils (1951), también distinguía entre tres tipos de actitudes: orientación cognitiva, afectiva y evaluativa. La orientación cognitiva se basa en conocimientos y creencias sobre el sistema político, los políticos y demás elementos. Las orientaciones afectivas son sentimientos hacia el sistema político, sus roles, personas y actuaciones. Las orientaciones evaluativas son juicios y opiniones sobre los objetos políticos, y habitualmente implica la mezcla de valores con información. 
Entre los primeros estudios de la imagen de partido y sus efectos se encuentran los de Trilling (1976) y Wattenberg (1986). Trilling, tras analizar un periodo entre 1952 y 1972 concluye que los impactos coyunturales (por ejemplo, la guerra de Vietnam) mostraban un efecto muy limitado sobre la imagen que los ciudadanos tenían de los partidos políticos en los Estados Unidos. Wattenberg, por su parte, estudiando el periodo de 1952 a 1984 destaca el debilitamiento de las políticas económicas o de bienestar como rasgo para identificar de forma específica a los dos partidos. En ese sentido, se produciría una tendencia de convergencia en los dos partidos hacia una especie de neutralidad o campo común de consenso en lo referido a las políticas económicas y de bienestar. Esta convergencia de políticas y consecuente disolución de las imágenes de partidos ha sido y es aún objeto de debate y estudio. Recientemente, para el caso norteamericano (Brewer, 2009), y en contradicción con la tesis de la pérdida de diferenciación en las imágenes de partido en Estados Unidos, tras evaluar las imágenes de partido en relación con diversas cleavages (raza, género, religión, clase) concluye la existencia de diferencias en los perfiles de los dos partidos mayoritarios, atendiendo grupos específicos en la opinión pública.

Estas imágenes se forman a lo largo de años, incluso décadas, y ayudan a los electores a identificar lo que los líderes políticos o los partidos plantean. Solo una imagen de partido sólidamente establecida permitiría a los políticos efectuar discursos «irónicos» en la medida que lo planteado sea ajeno a su imagen. No obstante, Brewer señala que las imágenes de los partidos mostrarían dinamismo y cambio, tal y como detectaba Sanders (1988). Al igual que los partidos políticos cambian en el tiempo, su imagen también se ve modificada de forma paulatina dependiendo de sus actuaciones políticas. Tanto en el sentido de diferenciarse como de difuminarse. En definitiva, la imagen de partido, siendo una característica por lo general estable, también experimenta, con el paso del tiempo y posibles cambios de programa ideológico o acción de gobierno, modificaciones que pueden llegar a redefinir su imagen.

Los partidos políticos son percibidos por la sociedad en función de diferentes dimensiones económicas, sociales, ideológicas. De hecho, los temas que caracterizan la imagen de partido en la opinión pública por lo habitual determinan indirectamente las líneas de conflicto (alternativa política) que pueden establecerse entre ellos. La debilitación de las diferencias en actuación política diluye los perfiles de la imagen de partido, reduciendo con ello la capacidad de ofrecer a los electores una opción política diferente. Un ejemplo de esto es la importante coincidencia en las políticas económicas del Partido Socialista Obrero Español y el Partido Popular, al emplear modelos de interpretación macroeconómica similares. La consecuencia en sus imágenes de partido es la eliminación de un perfil distintivo del socialismo (Alaminos y Penalva, 2013). Este proceso de 
confusión de perfiles y supresión de líneas de conflicto en los programas políticos entre partidos en su política económica ha sido una dinámica generalizada en muchas de las democracias europeas, con la consecuencia de difuminar los perfiles económicos y sociales de las imágenes de partido, reduciendo con ello su percepción como posibles alternativas y dejando abierta la puerta a movimientos populistas que proponen diferenciarse de las políticas indistintas de los partidos tradicionales. Una situación alternativa se produce creando un perfil diferenciado desde el ámbito de la propaganda política. Por ejemplo, cuando el programa económico electoral contradice las políticas en curso (caso del Partido Popular en las elecciones de 2011 en España), generando una diferenciación artificial para, posteriormente, mantener desde el Gobierno su continuación y profundización, contradiciendo su propio programa electoral. Como podremos observar más adelante, ese movimiento contracorriente en la derecha de los espacios de consenso que produce la misma lectura ideológica de la macroeconómica, le dio un importante beneficio electoral (mayoría absoluta) para después desplomarse rápidamente en su intención de voto y apoyo electoral.

Entre las consecuencias de la debilitación de los perfiles propios que definen la imagen de partido de los diferentes partidos políticos del sistema, Wattenberg (2000) propone una progresiva irrelevancia de los partidos políticos para los electorados. Una irrelevancia que podría decirse que es, entre otras causas, consecuencia de la convergencia en muchas de sus políticas (ya sea estableciéndolas o conservándolas) que los hace casi indistintos para los electorados de centro, con perfiles ideológicos bajos y orientados a resultados. En ese clima, los factores externos al sistema político adquieren una significación especial a efectos de la toma de decisiones.

En general, podemos asumir que esta imagen tiende a permanecer estable por periodos prolongados de tiempo y a modificarse según las políticas que adopte cuando el entorno social y económico sufra cambios importantes, así como por la imagen que los medios de comunicación trasmitan de ellos (Sanders, 1988). Los medios de comunicación ejercen un papel muy significativo en la modificación y difusión de una imagen de partido, llegando a generar movimientos electorales decisivos (Alaminos y Penalva, 2010).

En determinadas ocasiones, la imagen del líder - $\mathrm{y}$ en especial cuando es de nuevo cuño en la opinión pública nacional - se utiliza en combinación con la imagen de partido para vertebrar electorados. Un ejemplo es el caso de las elecciones generales de 1996 y 2000 en España. En aquella ocasión, la imagen del líder (Aznar) era presentada y percibida como mucho más moderada y centrista que la del partido que lideraba (Partido Popular), permitiendo efectuar una doble articulación ideológica que cubrió todo el espectro desde el centro a la extrema derecha. La imagen del líder llegaba a electorados 
centrados que el partido político (por su fuerte imagen conservadora) era incapaz de alcanzar. En cierto modo, los liderazgos ofrecen la posibilidad de presentar un nuevo objeto político, sin un pasado y capaz de mostrar perfiles diferenciados respecto a la oferta de los partidos, de imagen más difícil de cambiar. Tanto los recientes procesos en España (Pablo Iglesias, Albert Rivera) como en Francia (Emmanuel Macron) responden a líderes que capitalizan tener un perfil diferenciado de las «imágenes de partidos» en ese momento en el sistema electoral. Estos líderes, inicialmente libres del peso de la imagen de partido, poseen la ventaja durante un tiempo limitado. Tan pronto adquieren una imagen propia o una de partido asociada, esta actúa como un efecto de largo plazo que reduce la volatilidad de sus resultados. Así, aunque el liderazgo tiene un efecto bien definido sobre los electorados (Cohen, 2015), debe combinarse con la imagen del partido, un elemento de largo plazo que permanece activo, por lo general, por varias convocatorias electorales.

Como podemos observar, la catalogación entre largo, medio y corto plazo es una consideración relativa, orientada a destacar la lentitud del cambio que postula la lectura teórica del concepto. Es evidente que cada sociedad y cada partido político tienen su propia historia particular que da una forma u otra al cambio.

Es desde la lectura de su efecto menos duradero que se consideran los efectos a medio plazo, que en parte acostumbran a depender de una interpretación ex post de los datos a la luz de los resultados. Estos efectos están relacionados por lo general con la valoración de la actuación efectuada tanto por el Gobierno como por los partidos de la oposición. Esta influencia de la valoración de la actuación del partido sobre la movilización viene a ser formulada, en su exposición más simple, como que una valoración positiva de la actuación del Gobierno (por ejemplo, en la situación económica) refuerza sus resultados electorales, mientras que, en sentido contrario, una valoración negativa da más oportunidades de competir a los partidos de la oposición. En definitiva, que el cálculo electoral efectuado por los votantes se apoya más en la evaluación del pasado que en las promesas para el futuro. En un planteamiento puro, es la gestión del partido en el Gobierno la que recibe una recompensa o castigo en función de la valoración que obtiene. En ese sentido, el voto económico retrospectivo consideraría la gestión del periodo de gobierno.

Las premisas que dan forma a esta aproximación del voto retrospectivo se basan en la importancia de los votantes de centro y su naturaleza ideológica. Mientras que en la izquierda y la derecha los electorados tienen como referencia un conjunto de valores fundamentales, los electorados de centro poseen una mezcla de valores de izquierda y derecha. Algunos de sus principios ideológicos son de izquierda (por ejemplo, en lo social) mientras que otros son de derechas (por ejemplo, en lo económico). Por ello se 
considera que frecuentemente deciden sus votos no tanto en función de la ideología de los partidos o los programas que proponen, sino de la actuación de estos en el tiempo. Son varios los estudios empíricos (Campbell et al., 2010) que se concentran en determinar cómo para los electorados de centro lo importante en su decisión de voto es la actuación de los partidos y de los líderes políticos (su reflejo en la situación social y económica). Las promesas electorales o programas futuros tendrían desde esta teoría un peso mínimo sobre las decisiones de los votantes de centro.

Dos son los elementos clave: la experiencia pasada y la consideración de los partidos en la oposición, especialmente en el caso de sistemas bipartidistas.

Desde la óptica del voto retrospectivo, el futuro es pasado. Según Fiorina (1981), en la medida que la actuación en el pasado del partido en el Gobierno incluye las promesas cumplidas o incumplidas que se hicieron. En ese sentido, los futuros son evaluados retrospectivamente más como realización que como promesa. Esta idea fue propuesta por Walter Lippmann en la década de los años 20, siendo refinada en años posteriores por varios autores (Key, 1964; Tufte, 1978; Kramer, 1971; Fiorina, 1981), y se emplea en particular para el estudio de las elecciones presidenciales norteamericanas (Abramowitz, 2008; Holbrook, 2008; Lewis-Beck y Tien, 2008; Campbell, 2008; Erickson y Wlezien, 2008). Key (1964) destacaba cómo en la evaluación retrospectiva de la acción de gobierno que orienta el voto primaban los resultados sobre los medios, valorándose especialmente al Gobierno y, en menor medida, la actuación de la oposición, primando lo hecho en el pasado por encima de lo dicho sobre el futuro.

Se desprende de lo anterior que los nuevos liderazgos (como los ya comentados) escapan inicialmente de la teoría del voto retrospectivo. Los electorados no tienen una experiencia de gestión/actuación, por lo que su voto está más orientado hacia la expectativa que hacia la realización anterior. Sin embargo, cuando los electorados poseen una experiencia de actuación política, los hasta ese momento nuevos líderes y sus partidos comienzan a ser susceptibles de ser evaluados en su apoyo electoral desde la óptica del voto retrospectivo.

Para muchos autores, el voto retrospectivo no tiene como actor único al partido en el Gobierno. Los demás partidos, y en particular el principal partido de oposición, también son relevantes en esa evaluación retrospectiva. Downs (1957) propone que la evaluación retrospectiva incluye de manera necesaria a los partidos de oposición (especialmente en sistemas bipartidistas) en la medida que al realizar estos una actuación consistente en el tiempo (en lo hecho y dicho en el pasado, en definitiva, la fiabilidad de los partidos), también se utiliza comparativamente lo que hizo el partido ahora en la oposición cuando estuvo en el Gobierno como referencia para evaluar la actuación del actual Gobierno. En otras palabras, para valorar la actuación del partido en el Gobierno se 
utiliza no solo lo que hace, sino también lo que hizo el partido ahora en la oposición. Una valoración muy negativa del partido que sea alternativa de Gobierno modera la valoración de la gestión del partido gobernante.

Podemos apreciar como los conceptos referidos a la valoración retrospectiva y a la imagen de partido se entrecruzan de forma significativa. La imagen del partido de la oposición, en función de su última actuación de gobierno, permanece como factor evaluativo en el presente. Desde la experiencia práctica, la intersección de ambos conceptos es producto de que la eficacia en la gestión o actuación del partido se convierte en un rasgo característico de la imagen de partido, como propone Downs. Es algo que podremos apreciar perfectamente en el caso español.

Si bien la teoría del voto retrospectivo tiene una elevada aplicabilidad, es evidente que en múltiples ocasiones depende del contexto particular de cada elección (Kinder y Kiewiet 1991; Nadeau y Lewis-Beck 2001; Norpoth, 2002; Duch y Stevenson 2008). Entre estos elementos de variabilidad se encuentra, por ejemplo, si el candidato se presenta a reelección o no. Según varios autores (Campbell, 2010) el efecto electoral de una valoración positiva de la gestión se debilita cuando el jefe de Gobierno no se presenta como candidato a reelección. En otras palabras, el cambio de candidato produce que el partido no capitalice por completo los beneficios de una buena situación socioeconómica. En definitiva, los nuevos candidatos de un partido en el Gobierno no reciben todo el crédito que adquirió el anterior líder político en el Gobierno. Esto, según Campbell y otros, funciona también en el otro sentido. Cuando la evaluación de la actuación del presidente es muy negativa, en el caso norteamericano, su sucesor recibe un castigo menor que si él se presenta de nuevo a reelección.

Con todos los matices y condicionantes, las diferentes aproximaciones del modelo de voto retrospectivo (por ejemplo, donde la evaluación está basada en experiencias personales del votante o a partir de informaciones mediadas, incluida la selección de las fuentes de información), concluyen que los votantes favorecen al partido en el Gobierno cuando las condiciones económicas y sociales son buenas y, por el contrario, le penalizan cuando son malas. Es el caso del gobierno del PSOE y su actuación en la crisis económica que se inicia en 2007.

En la evaluación de los efectos de medio plazo se han empleado tanto las mediciones de valoración mediante encuestas como de forma indirecta, utilizando indicadores estadísticos referidos a la situación económica, como son el crecimiento económico, el desempleo, la inflación, etc. (Bartels y Zaller, 2001; Abramowitz, 2008; Erikson y Wlezien, 2008; Campbell, 2008b; Fair, 2009). En este segundo caso — de empleo de indicadores estadísticos de la situación económica - debe efectuarse una inferencia lógica que atribuye la mejora de la situación económica (o su empeoramiento) directa- 
mente al Gobierno. En el caso de la valoración de la actuación de gobierno (o partido de oposición) mediante encuestas esta inferencia no es necesaria. Es la empleada en el diseño del análisis que aquí se presenta.

Si bien en este planteamiento se acostumbra a enfatizar la dimensión racional mediante un sistema de recompensa o castigo, lo cierto es que los factores subjetivos (ideológicos) también condicionan la valoración de la actuación. En definitiva, determinadas políticas impopulares no son activadas para reducir la mala valoración, saliendo de la agenda política. Este hecho ha sido el que, por ejemplo, en el caso reciente de España, ha evitado las actuaciones legislativas del gobierno conservador del Partido Popular (con mayoría absoluta en las elecciones de 2011) orientadas a modificar la regulación del matrimonio homosexual o la interrupción del embarazo, aun cuando desde la oposición el partido activó procedimientos legales en su contra. En España el caso del Partido Popular es en especial paradójico, dado que la contradicción entre su imagen de partido posicionada radicalmente en temas sociales y su no actuación en la práctica como política de gobierno es permanente.

Entre estos factores de medio plazo se acostumbra a incluir el efecto del «coste de gobernar» (Paldan, 1991). Según plantea, el gobernar tiene como resultado una fatiga con consecuencias electorales. Este efecto es más evidente en los sistemas electorales sin limitación de mandato (como España), y es visible en la evolución del PSOE entre las elecciones generales de 1982 y 1989. Tras las cuatro legislaturas de Felipe González como presidente del Gobierno, los dos presidentes posteriores (Aznar y Zapatero) lo fueron durante dos legislaturas y no se presentaron como candidatos a la tercera. En ese sentido, la fatiga de gobierno tiene actualmente un efecto limitado, dado que los datos empleados aquí comienzan en 1996.

Un tercer efecto sobre los resultados procede de los impactos que se producen en el corto plazo. En el caso de España, impactos significativos con carácter global sobre los electorados fueron, por ejemplo, el intento de golpe de estado de Tejero y su efecto de movilización sobre las elecciones generales de 1982 o las consecuencias del atentado del 11 de marzo sobre las elecciones generales de 2004. Estos impactos, en su mayoría imprevisibles, modifican las tendencias de voto al movilizar o desmovilizar a los electorados.

Entre estos efectos a corto plazo se incluyen también las campañas electorales. En sí mismas, las campañas electorales son acciones de comunicación planificada orientada a efectuar un impacto en la opinión pública de los electorados. En definitiva, de movilizar o desmovilizar electoralmente el apoyo a partidos, facilitando elementos subjetivos e información objetiva destinada a condicionar la toma de decisión final del votante. Estos impactos han sido estudiados de manera profusa desde el ámbito de la comunica- 
ción, de la politología y la sociología, tanto para diagnosticar sus efectos sobre la opinión pública (Campbell, Cherry y Wink, 1992; Alvarez, 1997; Erikson y Wlezien, 1999; Wlezien y Erikson, 2002; Romer et al., 2006; Panagopoulos, 2009) como la eficacia de sus actuaciones en la movilización electoral (Holbrook, 1996; Shaw, 1999; Wlezien y Erikson, 2002b; Zaller, 2002; Hillygus y Jackman, 2003; Vavreck, 2009; González Rodríguez y Bouza, 2009).

La campaña electoral es un periodo especial en el estudio de los electorados. La política se convierte en uno de los temas centrales de agenda en los medios y en la vida cotidiana. La proximidad a la fecha para tomar una decisión (abstenerse o votar a partido, blanco o nulo) es un límite temporal objetivo, el final de un periodo lleno de información, presión ideológica y propaganda electoral. Por lo general, la sucesión de información, eventos relevantes y mensajes de los candidatos introduce un elemento de volatilidad entre los electorados más indecisos (Gelman y King, 1993; Stevenson y Vavreck, 2000; Arceneaux 2006; Alaminos, 2015), con frecuencia expresada mediante la no respuesta parcial (no sabe o no contesta). La información de los medios durante la campaña puede, en algunos casos, modificar sensiblemente la imagen pública de los candidatos llevando de forma coyuntural a los electorados (bajo la presión psicológica y social del momento) a expresar una intención de voto diferente a la que finalmente efectuará (Zaller, 1992).

Como se ha podido considerar, son varios los elementos que influyen en la estructura electoral. Desde un punto de vista longitudinal, se han descrito los de largo plazo (identificación partidista, voto militante, imagen de partido), los de medio (voto retrospectivo, coste de gobernar) y los de corto (campaña electoral e impactos imprevistos).

En este artículo vamos a tener en cuenta desde el punto de vista longitudinal la relación observada entre varios de estos efectos y la intención de voto de los dos partidos hasta hace poco mayoritarios en España, el Partido Popular y el Partido Socialista Obrero Español. En particular, se evaluará especialmente el efecto del voto retrospectivo con la intención de voto y su interacción con la imagen de partido de ambos.

\section{EL CAMBIO DE ESTRUCTURA: ELECTORES Y PARTIDOS}

En este análisis se consideran únicamente el Partido Popular y el Partido Socialista Obrero Español. En cierto sentido, está condicionado por la estructura bipartidista de los datos que ofrece el CIS (partido en el Gobierno y principal partido en la oposición), pero también por la realidad hasta las elecciones generales de 2015. Las elecciones generales en España han estado protagonizadas desde 1989 por dos partidos que recogían 
un apoyo mayoritario del electorado (González Rodríguez y Bouza, 2009). En el caso del PSOE, ya desde 1982 mostró su capacidad de liderazgo en el sistema de partidos. En la derecha, el Partido Popular apareció en 1989 como refundación de los fragmentos políticos del centro derecha y derecha agrupados hasta entonces en Coalición Popular. Una derecha que, tras la pérdida de notoriedad de Fuerza Nueva, alcanzaba a cubrir todo el espectro conservador en España.

La capacidad electoral de estos dos partidos, en resumen, se aprecia en dos evidencias: los dos partidos se han alternado en el Gobierno de la nación sin necesidad de establecer coaliciones (aunque sí obteniendo apoyos puntuales de las fuerzas nacionalistas), y entre los dos obtuvieron entre el 74 y el 84 por ciento del voto a candidaturas en las elecciones generales. Esta situación cambia en las elecciones generales de 2015, con la irrupción de partidos como Podemos o Ciudadanos que canalizan electoralmente el descontento ciudadano, incrementando con ellos el multipartidismo en España.

\section{TABLA 1}

Suma del voto válido al PP y PSOE en elecciones generales

(1993 a 2016)

\begin{tabular}{cc}
\hline G-2016 & 56,1 \\
G-2015 & 51,1 \\
G-2011 & 74,4 \\
G-2008 & 84,7 \\
G-2004 & 81,6 \\
G-2000 & 79,9 \\
G-1996 & 77,2 \\
G-1993 & 74,1 \\
\hline
\end{tabular}

Fuente: elaboración propia sobre datos MIR

De hecho, la alternancia en el Gobierno de los dos partidos ha estado siempre rodeada de situaciones dramáticas o especialmente tensas, como fue en 1996 (Alaminos y Penalva, 2010), resultado de una campaña coordinada entre medios de comunicación para promocionar la alternancia del PP con el PSOE; en 2004, en el contexto de unos graves atentados islamistas, una deficiente comunicación de los hechos y la falta de transparencia por parte del gobierno del PP; así como en 2011, en medio de una vorágine de crisis económica y política mal gestionada por el Gobierno. En la experiencia electoral española, los cambios de partido en el Gobierno están asociados a situaciones excepcionales, en un sentido u otro. 
Sin embargo, a pesar de las traumáticas alternancias electorales en el Gobierno, como observaremos, la tendencia que redefinía los parámetros de funcionamiento electoral de estos dos partidos configuraba un nuevo escenario paulatinamente, cuya constitución definitiva se expresaría con un impacto ${ }^{3}$, primero social y después político (surgimiento de Podemos).

La evolución electoral de los nuevos partidos es, en la actualidad, una incógnita. Como señalan Tezanos y Luena (2017) para el caso de Podemos, tan previsible es su permanencia en el sistema como su desaparición repentina. Ambos casos son factibles, en la medida que puede darse una desaparición como consecuencia de su debilitamiento por fragmentación territorial (por ejemplo, en Cataluña o Andalucía) e ideológica (por ejemplo, los sectores anticapitalistas). No obstante, también podría darse una estabilización, y ocuparía el espacio hasta ahora propio de Izquierda Unida. Lo cierto es que, basándose en los datos actuales, parece muy improbable, tras el diseño organizacional establecido (tanto en Ciudadanos como en Podemos se han consolidado fórmulas de decisión muy centralizadas), que desde los nuevos partidos se propongan fórmulas alternativas de representación democrática. En ese sentido, los dos nuevos partidos han sido incapaces de responder a las demandas de la sociedad referidas a la regeneración de las formas organizacionales de una democracia moderna.

En este artículo se va a analizar, mediante algunas variables significativas, la evolución del bipartidismo en España desde la primera alternancia en el Gobierno en 1996. Para ello, se estudiará la valoración de la gestión y actuación del Partido Popular y del PSOE junto con su intención de voto. El estudio de la dinámica de la valoración de ambos partidos, desde el punto de vista temporal, ofrecerá información sobre su incorporación o no a la imagen de partido, dependiendo de la presencia o no de cambios de nivel significativos en las diferentes legislaturas. En cierto modo, los datos también facilitan la respuesta de hasta qué punto era previsible la crisis del modelo bipartidista en el sistema parlamentario español.

Las variables utilizadas son: la serie de intención directa de voto y la valoración de la gestión y actuación del PP y del PSOE, tanto en el Gobierno como en la oposición. Es evidente el peso de las demás opciones políticas en el sistema electoral español (tanto territoriales como ideológicas). Sin embargo, limitar el análisis al PP y al PSOE viene dado por la disponibilidad de datos y por el hecho de que ambos han sido los dos únicos partidos de Gobierno a nivel nacional hasta la actualidad.

${ }^{3}$ El impacto social que produjo el efecto catártico del 15M de 2011 (con su representación simbólica en la Puerta del Sol de Madrid) fue, según Alaminos y Penalva (2013), el resultado de la interacción de dos crisis: la de la corrupción y la económica. 


\section{LOS DATOS}

Los datos procedentes de encuestas de opinión, cuando reflejan los cambios producidos en un periodo mediante series temporales, presentan sus propias dificultades metodológicas, como son las interrupciones en la serie o el no equiespaciado de los datos. Otras proceden de la propia naturaleza estadística de la encuesta de opinión y su carácter inferencial. Habitualmente las mediciones (por ejemplo, valoración de líderes, evaluación de situación, intención de voto, etc.) contienen un elemento de error que procede tanto de la variabilidad misma inherente al muestreo como de otras fuentes diversas de error (Crespi, 1988; Groves, 1989; Alaminos, 1991; Francés et al., 2014).

Cuando las encuestas utilizadas proceden de varias fuentes (diferentes empresas o instituciones), la variabilidad de los diseños de muestreo, el empleo de ponderaciones o diferentes fraseos y opciones de cierre introducen un error adicional cuando son utilizadas de forma conjunta en un mismo análisis (Weisberg 2005; Biemer, 2010). A estos errores no intencionales procedentes de la variabilidad de diseños diferentes cabe añadir el denominado house effects, que aparece cuando una determinada compañía o empresa produce estimados que están sesgados sistemáticamente a favor o en contra de determinados líderes o partidos políticos (Alaminos, 1994; McDermott y Frankovic, 2003; Wlezien y Erikson, 2007). Cuando existen múltiples fuentes alternativas (diferentes encuestas de diferentes empresas), este efecto «casero» se minimiza mediante la integración combinada de los estimados procedentes de diferentes fuentes (Traugott y Wlezien, 2009). En el caso de las series temporales construidas sobre múltiples fuentes de información de encuestas, es factible establecer también sistemas de ponderación y suavización (Erikson y Wlezien, 1999; Jackman, 2005; Wlezien y Erikson, 2007) que permiten integrar la posible variabilidad procedente de la fuente. No obstante, el efecto «casero» es especialmente perjudicial cuando estas encuestas sesgadas son fuentes únicas para determinados puntos temporales. Esta información anómala introduce distorsiones en las series que dificultan la detección de patrones o tendencias claras en la opinión pública.

En este caso, este problema no es significativo en la medida que se utiliza una única fuente de información - las encuestas de opinión del Centro de Investigaciones Sociológicas - consistente en el tiempo en sus diseños muestrales y fraseos. Las series están bastante completas, presentando casos perdidos para la valoración de Gobierno y oposición en los periodos de Gobierno en funciones. La serie mantiene una periodicidad trimestral.

Los datos que se van a utilizar proceden de los barómetros del Centro de Investigaciones Sociológicas, y, en particular, de su sistema de indicadores del sistema político, cuya 
operativización viene explicada en su página web ${ }^{4}$. Tal y como detalla, las preguntas de los barómetros que se consideran para estos indicadores son dos, reformuladas según el partido en el Gobierno. Así, redactada del siguiente modo: «En su conjunto, ¿cómo calificaría usted la gestión que está haciendo el gobierno del PSOE?», o, en su caso, «En su conjunto, ¿cómo calificaría usted la gestión que está haciendo el gobierno del PP?». La misma lógica se aplica para el partido que en esa ocasión se encuentre en la oposición: «En general, ¿cómo calificaría usted la actuación política que está teniendo el PSOE en la oposición?» o «En general, ¿cómo calificaría usted la actuación política que está teniendo el PP en la oposición?». En definitiva, dos preguntas que, según el partido en el Gobierno o en la oposición, cambian el objeto de valoración. Unas se refieren al PSOE en el Gobierno o en la oposición, mientras que las otras preguntan lo mismo para el PP. Todas ellas ofrecen idénticas opciones de respuesta: «muy buena», «buena», «regular», «mala» o «muy mala». Como informa el CIS, estas preguntas se incluyen en los barómetros del primer mes para cada trimestre desde 1996. A partir de estas preguntas, se construyen, en primer lugar, las series de Valoración de la Labor del Gobierno (ILG) y Valoración de la Labor del Primer Partido de la Oposición (ILO). En el caso español, dada la alternancia establecida hasta ahora entre dos partidos en el Gobierno (PSOE y PP), al evaluar el comportamiento del Gobierno y de la oposición se están evaluando de hecho a los dos partidos.

Ambos indicadores ponderan las proporciones de cada categoría, con 100 para la valoración «muy buena» hasta 0 para la categoría «muy mala». Posteriormente, dividen por la suma de las proporciones para normalizar el rango de variación entre 0 y 100 (Alaminos et al., 2015). Valores próximos a cero expresan una mala valoración del partido (gestión/actuación) mientras que próximos a cien indican lo contrario, una excelente valoración. Según la formulación propuesta por el Centro de Investigaciones Sociológicas:

- Indicador de la Labor del Gobierno (ILG):

$$
I L G=\frac{100 \cdot p_{1}+75 \cdot p_{2}+50 \cdot p_{3}+25 \cdot p_{4}+0 \cdot p_{5}}{p_{1}+p_{2}+p_{3}+p_{4}+p_{5}}
$$

- Indicador de la Labor de la Oposición (ILO):

$$
I L O=\frac{100 \cdot p_{1}+75 \cdot p_{2}+50 \cdot p_{3}+25 \cdot p_{4}+0 \cdot p_{5}}{p_{1}+p_{2}+p_{3}+p_{4}+p_{5}}
$$

\footnotetext{
${ }^{4}$ http://www.cis.es/cis/opencms/ES/11_barometros/metodologia.html\#ISPGO
} 
La normalización del indicador hace que los valores próximos a 100 expresen una elevada valoración del partido considerado entre una mayoría de población. De hecho, 100 significa que toda la población que evalúa lo hace de forma excelente. Un valor de 0 indica lo contrario, con un rechazo absoluto a la gestión o actuación del partido. En su recorrido interno, diferentes combinaciones pueden dar lugar a un mismo valor del indicador, por lo que es insensible a la reorganización interna de segmentos de población. Así, dos segmentos electorales polarizados con valoraciones extremas podrían dar un valor equivalente a una población homogénea con valoraciones moderadas.

Consideradas las series que definen las alternativas de respuesta, el indicador parece reproducir de forma ajustada la opinión media del conjunto de la muestra. En especial, dado que el declive de los dos partidos considerados (PP y PSOE) ha sido consistente en el tiempo, reduciendo la magnitud del efecto de la polarización recíproca de los electorados de los dos partidos.

Dado el procedimiento de elaboración del índice, antes de su análisis es preciso efectuar un control metodológico de la variabilidad muestral capturada de hecho por dicho indicador. Este índice se construye de forma directa sobre los porcentajes de respuesta a las preguntas, excluyendo la no respuesta parcial. Esta exclusión del «no sabe» y del «no contesta» puede influir en la evolución de los indicadores al reducir la población sobre la que se aplica (no toda la muestra) y elevar el impacto de subpoblaciones. El efecto sobre las subpoblaciones, como muestra Alaminos (2012), puede influir de forma significativa sobre las relaciones que se estudien empíricamente. Para controlar el posible efecto de la no respuesta parcial se han comprobado su nivel en cinco momentos de la serie. La no respuesta parcial en 1997 es para ILG de $8,1 \% ; 5,9 \%$ en $2002 ; 4,3 \%$ en $2007 ; 5,6 \%$ en 2012 y $2,1 \%$ en 2017 . ILO acumula en cada año una no respuesta parcial de $13,3 \%$ en $1997 ; 8,9 \%$ en $2002 ; 5,7 \%$ en $2007 ; 6,6 \%$ en 2012 y $4,1 \%$ en 2017. No se aprecia un incremento significativo en la evolución de la no respuesta parcial (más bien un descenso progresivo de esta en la valoración del partido de la oposición), de modo que las tendencias estudiadas no están condicionadas significativamente por la estructura de la no respuesta parcial, representando de manera adecuada la variabilidad muestral.

TABLA 2

No respuesta parcial de las variables de valoración del PP y PSOE

\begin{tabular}{lrrrrr}
\hline \multirow{2}{*}{ Variable } & $\mathbf{1 9 9 7}$ & $\mathbf{2 0 0 2}$ & $\mathbf{2 0 0 7}$ & $\mathbf{2 0 1 2}$ & $\mathbf{2 0 1 7}$ \\
\cline { 2 - 6 } & Abr-97 & Abr-02 & Abr-07 & Abr-12 & Abr-17 \\
\hline Actuación del Gobierno & $8,1 \%$ & $5,9 \%$ & $4,3 \%$ & $5,6 \%$ & $2,1 \%$ \\
Actuación primer partido de la oposición & $13,3 \%$ & $8,9 \%$ & $5,7 \%$ & $6,6 \%$ & $4,1 \%$ \\
\hline
\end{tabular}

Fuente: elaboración propia a partir de barómetros del Centro de Investigaciones Sociológicas de abril de 1997, 2002, 2007,2012 y 2017 
La segunda variable tomada en consideración es la intención directa de voto a partidos en elecciones generales. Su fraseo es «Suponiendo que mañana se celebrasen elecciones generales, es decir, al Parlamento español, ¿a qué partido votaría usted?» Y como respuesta, los partidos políticos que mencione el entrevistado. Esta serie temporal recoge un estado de opinión explícito, es decir, el de aquellos ciudadanos que no tienen inconveniente en expresar su preferencia por un partido u otro. En cierto sentido, como hemos visto para varios autores, indica el «suelo» del apoyo electoral con que cuenta el partido político.

En relación con los datos, se ha procedido a su integración unificando la valoración de la gestión (como Gobierno) y la actuación (como oposición) de cada uno de los dos partidos. Es decir, se ha tomado la valoración del partido político, sea en el Gobierno o en la oposición, como criterio para la formación de las series. De este modo, las series expresan la valoración de la gestión y la actuación de los partidos, más allá de la función de gobernar o no. En cierto sentido, define una aproximación a la valoración retrospectiva de la capacidad que ha mostrado el partido para recoger y afrontar los problemas de los ciudadanos (Downs, 1957). Esta integración de las series tomando como referencia al partido explica las diferencias con las series publicadas por el CIS, que tienen como referencia el estar en el Gobierno o en la oposición. Los datos son los mismos, si bien organizados por partidos y no por función (Gobierno u oposición). En ese sentido, se aproxima en mayor grado a la imagen de la capacidad de actuación/gestión del partido que a las responsabilidades políticas del momento.

Esta integración de las series tomando como sujeto al partido permite estudiar tanto la dinámica del partido en la opinión pública como identificar el efecto de la acción de gobierno, en la medida que las legislaturas son fácilmente identificables a partir de las fechas de la serie.

\section{LAS DINÁMICAS DEL VOTO RETROSPECTIVO}

Desde el punto de vista del voto retrospectivo, cabe señalar que las tendencias de valoración de la actuación del Gobierno y del principal partido de la oposición (alternativamente Partido Socialista Obrero Español y Partido Popular) y la de intención de voto muestran una coordinación muy importante. Esta coordinación permite identificar de manera precisa un periodo atípico en las tendencias del Partido Popular que coincide con la grave crisis económica en el segundo mandato del presidente Zapatero. A continuación, vamos a describir y analizar las dinámicas para el Partido Socialista Obrero Español y para el Partido Popular. Después, tras evaluar la relación entre las series de inten- 
ción de voto y valoración de cada partido, se efectúa un control metodológico orientado a validar en el nivel micro (individuos) la relación apreciada en el nivel macro (series).

\section{EL APOYO AL PP: INTENCIÓN DE VOTOY VALORACIÓN DE SU ACTUACIÓN/GESTIÓN}

Vamos a considerar el caso del Partido Popular. El gráfico 1 muestra la dinámica que ha seguido la valoración de la gestión/actuación del PP en forma de serie temporal. Junto a ella, se muestra la serie temporal con la intención de voto al PP en elecciones generales, medida en la misma encuesta que la valoración. Las series han sido interpoladas linealmente para los casos perdidos en la variable de valoración en las mismas fechas por las dos series (enero de 2012 y el intervalo entre las elecciones de diciembre de 2015 y junio de 2016).

La serie de valoración de la actuación/gestión, junto a la intención de voto del PP, muestra una tendencia creciente en 1996 que culmina con la mayoría absoluta en las elecciones de 2000. Ambas series inician un declive, especialmente acentuado en el caso de la valoración del PP, e iniciarían una fase estacionaria hasta 2008. En esta época se produce la inversión en la relación entre ambas series. Mientras que con carácter global la serie de valoración del PP continúa con una tendencia decreciente, la intención de voto inicia una recuperación hasta 2011, donde retomaría la sincronización con la serie de valoración en el sentido de continuar su declive.

En el verano de 2015 se inicia una nueva recuperación en ambas series, si bien los datos aún son insuficientes para establecer si es un simple rebote o un retorno a la estructura de bipartidismo, considerando además el efecto que la interpolación de enero a octubre de 2016 puede tener en este periodo.

$\mathrm{Si}$ atendemos a la relación entre las dos series, de confianza en el PP y la intención de voto, observamos una evidente coordinación entre ellas, con un periodo de cambio de signo en dicha coordinación, que definirían tres etapas: dos de coordinación positiva entre las dos series y otra de coordinación negativa. Es decir, correlación cruzada negativa entre 2008 y 2011, y positiva entre 1996 a 2008 y desde 2011 a la actualidad. En ese sentido, destaca la excepcionalidad del periodo entre 2008 y 2011, con la crisis económica y social en España ya presente de forma clara en la opinión pública y publicada. Esta excepcionalidad hace prácticamente converger la valoración de la actuación/gestión del PP con su intención de voto.

El declive continuado en la valoración de la capacidad del PP (actuación/gestión) entre 2000 y 2015 es muy significativo (en la medida que encuentra reflejo en la del PSOE) y ya anticipaba la actual crisis del bipartidismo (Molto, 2013). 


\section{GRÁFICO 1}

Series trimestrales de intención de voto y valoración actuación/gestión del PP

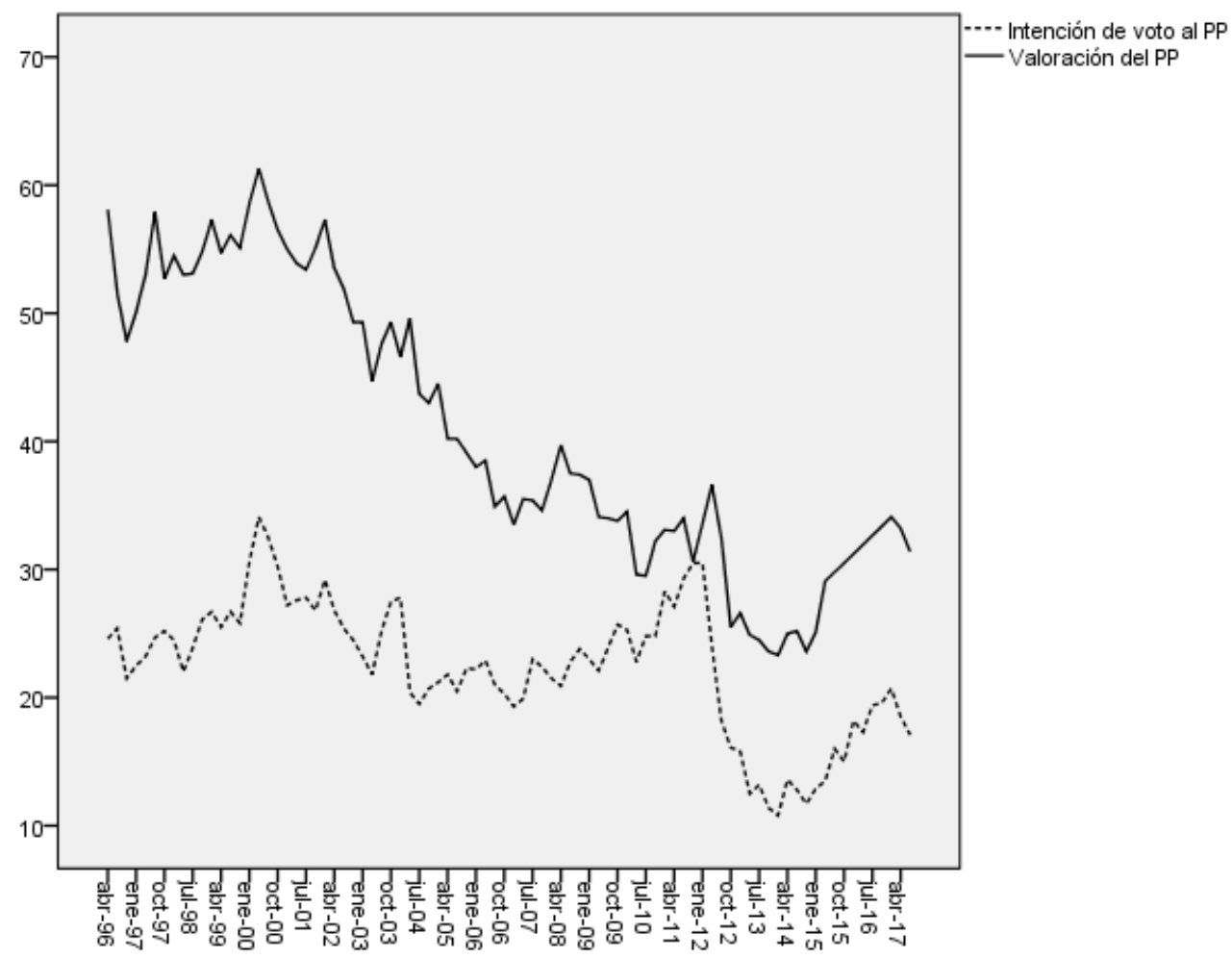

fecha

Fuente: elaboración propia con series indicadoras del CIS. Interpolación lineal. Series trimestrales

Las series muestran un clima continuado de deterioro de la confianza en la capacidad de gestión/actuación del PP, con un rebote en 2015. Como etapa atípica, en el periodo de gobierno socialista durante la crisis, tras 2008, se incrementa la intención de voto al PP mientras continúa su declive en la confianza general en el conjunto de la población, hasta converger. En ese sentido, el electorado conservador se movilizó a contracorriente del clima general negativo sobre el PP. Un segmento electoral que define una subpoblación en contradicción con la opinión generalizada. Es interesante recordar que la serie de valoración de la actuación/gestión expresa la opinión del conjunto de la sociedad y, en ese sentido, en cierto modo describe un clima negativo más generalizado cuanto más reducido es el porcentaje de valoración positiva. 
Si consideramos la correlación cruzada entre las dos series (sabiendo que contiene el periodo de 2008 a 2011 de correlación cruzada negativa), y tras la diferenciación de 1 para retirar la integración observada en las dos series, se aprecia una correlación cruzada general positiva (cuando una crece la otra también y viceversa) de .33. Asimismo, destaca la anticipación en un lag (trimestre) de la intención de voto sobre la valoración de la gestión/actuación del PP. En este caso, la evolución en la intención de voto anticipa la valoración del PP en el siguiente trimestre, con una correlación significativa de .26.

\section{GRÁFICO 2}

Correlación cruzada entre intención de voto al PP y la valoración de su actuación/gestión

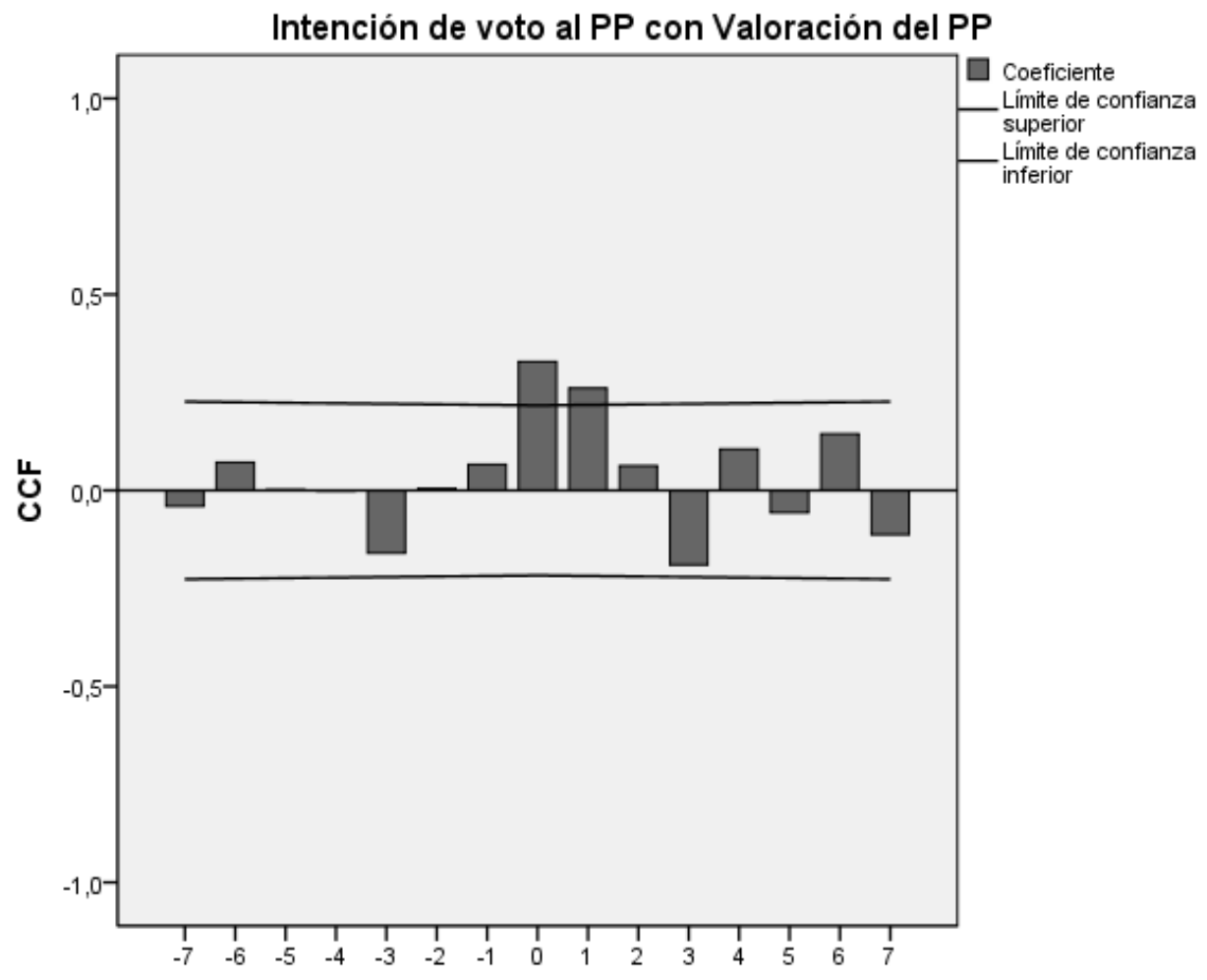

Núm. de retardos

Fuente: elaboración propia con series indicadoras del CIS. Interpolación lineal. Series trimestrales diferenciadas (1)

Cuando se analizan independientemente los tres periodos considerados de coordinación (1996-2008, 2008-2011 y 2011 hasta la actualidad), tras diferenciar en 1, se aprecia correlación positiva entre ambas series para los periodos uno y tres y correlación nega- 
tiva para el periodo de 2008 a 2011. Este periodo a contracorriente de la intención de voto del PP reduce la correlación cruzada total considerada con anterioridad. Por lo general, la crisis entre 2008 y 2011 es tan importante y sus efectos electorales tan atípicos dentro de la tendencia general del PP que al trabajar con diferentes modelos y retirar los resultados electorales de 2011 mejora sensiblemente su ajuste y significación (Alaminos y Alaminos-Fernández, 2017).

\section{EL APOYO AL PSOE: INTENCIÓN DE VOTO Y VALORACIÓN DE SU ACTUACIÓN/GESTIÓN}

En el caso del PSOE, la intención de voto muestra una leve tendencia decreciente entre 1996 y 2000, y creciente entre 2000 y 2004. En el caso de la valoración de la gestión/actuación del PSOE, se aprecia una cierta estacionariedad en las dos legislaturas, si bien con un cambio nivel (algo más elevado) en la segunda entre 2000 y 2004. En conjunto, definen un periodo relativamente estacionario. La elección atípica en el caso del PSOE fueron las elecciones generales de 2004. Las series muestran el brusco cambio de nivel característico de las intervenciones. Como es bien conocido, las elecciones sucedieron después de unos atentados brutales que impactaron la opinión pública. La deficiente transparencia en las políticas de comunicación del entonces gobierno del PP y la sospecha de posible distorsión de la información (atribuyendo el atentado a la banda terrorista ETA) generaron un clima propicio al vuelco electoral.

El impacto se recoge tanto en la valoración de la actuación/gestión del PSOE como en la serie de intención de voto, que cambian bruscamente de nivel de forma coordinada. La serie pierde memoria con rapidez, recuperando un nivel estacionario más o menos en enero de 2005. Un nivel más elevado que el mostrado en el periodo 2000 a 2004 y que continuaría hasta poco después de las elecciones de 2008, cuando la dureza de la crisis económica se reflejó de manera clara en las políticas económicas y sociales del Gobierno. A finales de 2009, tanto la confianza en la gestión/actuación del PSOE como la intención de voto se desploman. Desde el punto de vista de los análisis de intervención, la crisis económica impacta negativamente en la valoración del PSOE, así como en su intención de voto, con un deterioro progresivo y acelerado. Tocaría fondo en primavera-verano de 2014 para, dentro de una cierta estacionariedad (con un inicio de crecimiento y posterior decrecimiento, consecuencia de los problemas internos del PSOE), iniciar una recuperación en primavera-verano de 2017. También en el caso del PSOE permanece la duda de si inicia una recuperación tendencial, tanto de la confianza en su actuación/gestión como de la intención de voto, o por el contrario es un rebote puntual dentro de una estacionariedad. 


\section{GRÁFICO 3}

Series trimestrales de intención de voto y valoración actuación/gestión del PSOE

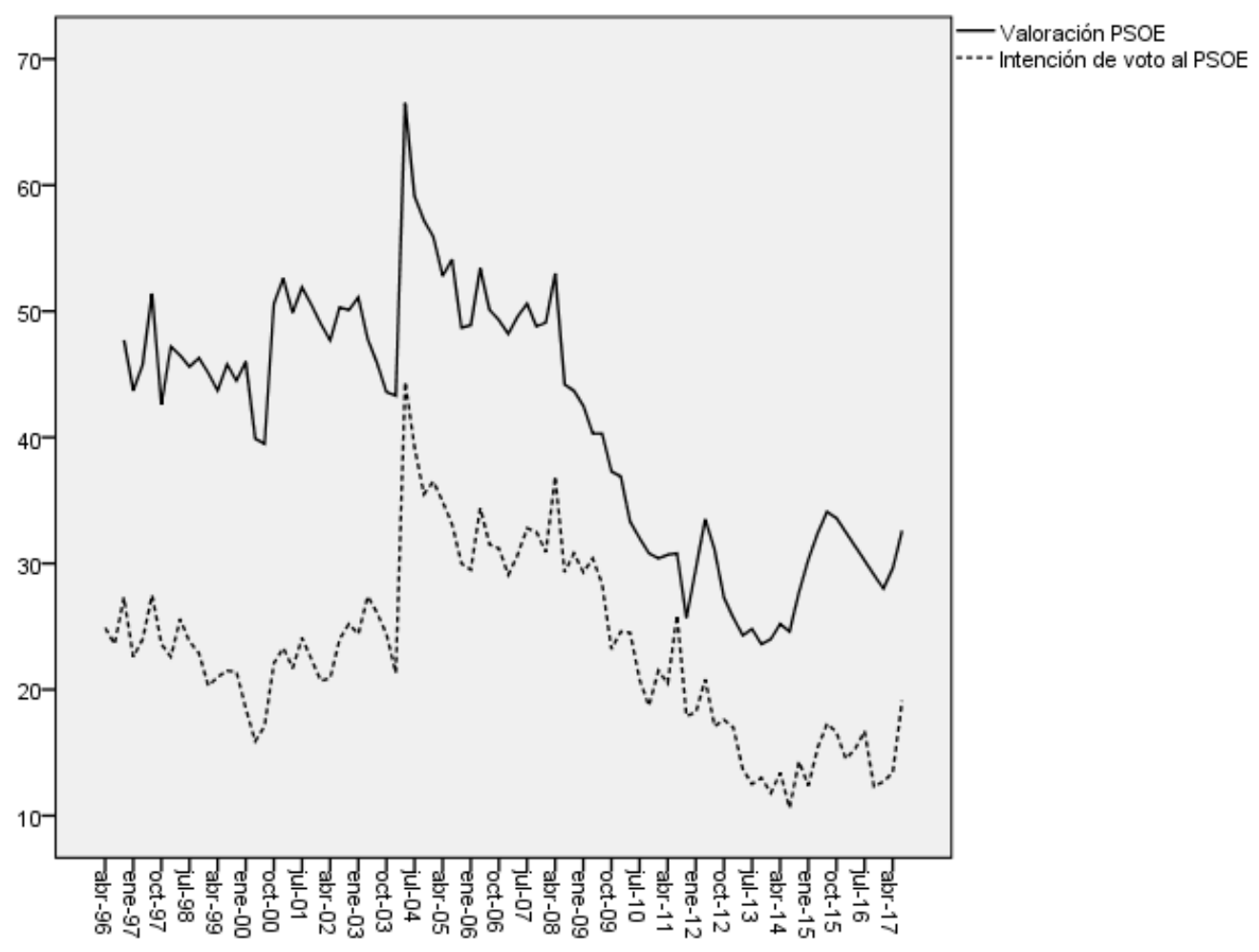

fecha

Fuente: elaboración propia con series indicadoras del CIS. Interpolación lineal. Series trimestrales

A diferencia de las series del PP, el PSOE mantiene una coordinación elevada entre la valoración pública de su gestión/actuación y la intención de voto para todo el periodo considerado. Las dos series muestran integración negativa, por lo que, tras una diferenciación de 1, la correlación cruzada entre las dos series ofrece una correlación muy elevada de .81 en el lag 0 . En otras palabras, las dos series muestran una relación muy importante entre ellas. 


\section{GRÁFICO 4}

Correlación cruzada entre intención de voto al PSOE y la valoración de su actuación/gestión

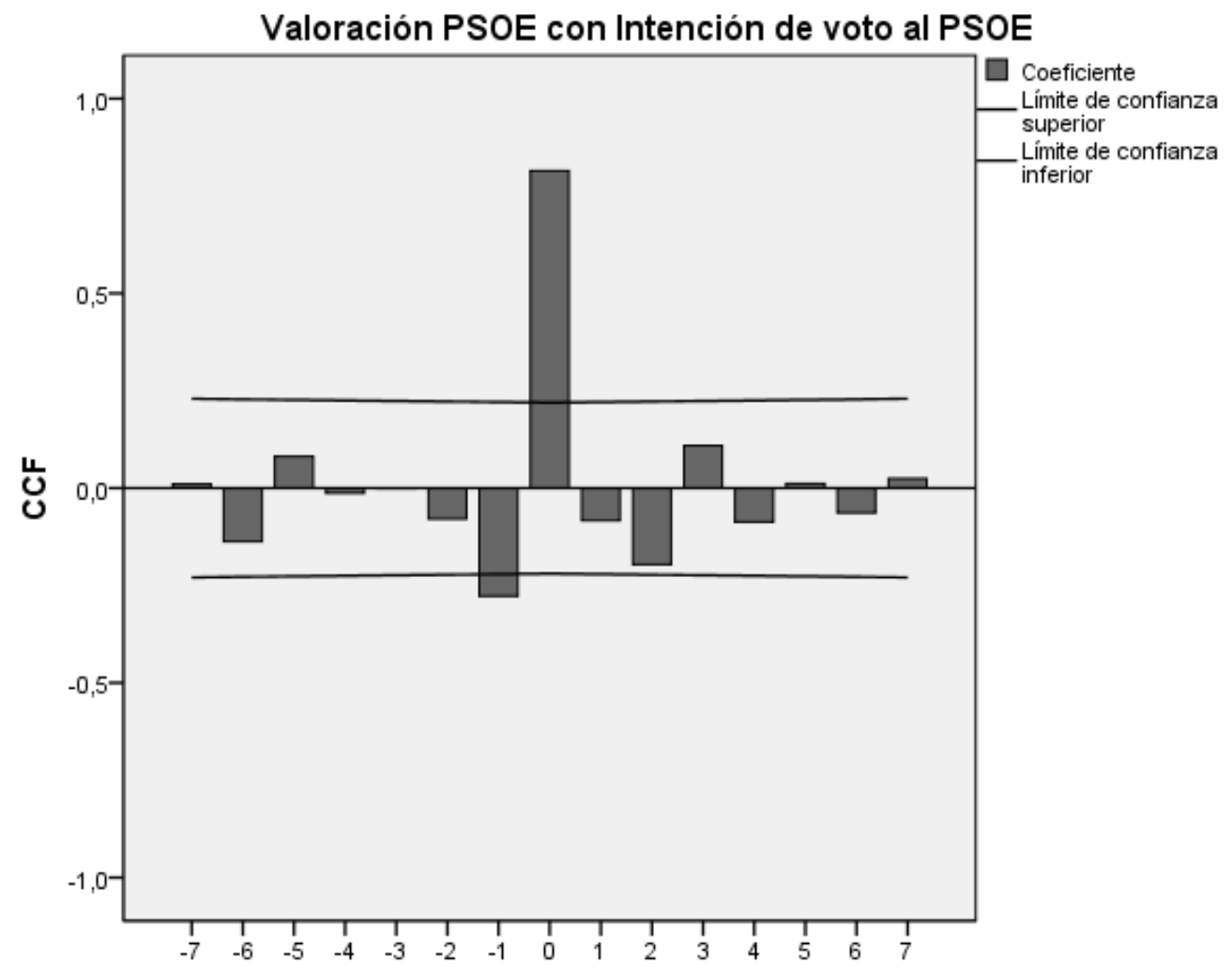

Núm. de retardos

Fuente: elaboración propia con series indicadoras del CIS. Interpolación lineal. Series trimestrales diferenciadas (1)

El análisis longitudinal confirma la importancia de la actuación/gestión del PSOE entre su electorado. La elevada coordinación entre las dos series (intención de voto y valoración) expresa que el PSOE es evaluado muy de cerca por la sociedad española y que sus electorados son muy sensibles a las actuaciones que realice, tanto en la oposición como en el Gobierno. Es interesante, de acuerdo con Downs, lo relevante que es la actuación en el Gobierno, pero también en la oposición. La imagen que ofrece un partido sobre su capacidad y fiabilidad se desarrolla también fuera del Gobierno, siendo relevantes las crisis de organización y las soluciones que se adopten. 


\section{VALIDACIÓN MICRO}

El análisis anterior ha tenido en consideración las series temporales, empleando valores agregados. Como es bien sabido, la relación entre agregados puede estar afectada directamente por la falacia ecológica, según la cual los cambios aparentes pueden proceder de diferentes composiciones de población. Por ello, para establecer la conexión entre la valoración de la actuación/gestión desarrollada por el PP y el PSOE, se han empleado los microdatos, con la finalidad de determinar si la relación entre la intención de voto al PP que enuncia un sujeto está asociada con la valoración de la actuación del PP que hace ese mismo sujeto. En ese sentido, la correlación entre series observada a nivel macro se vería consolidada desde una estructura de correlación micro (covariación entre las opiniones de los individuos considerados de forma desagregada).

Para responder a la pregunta sobre si la intención de voto y la valoración de los partidos PP y PSOE están relacionadas, se ha efectuado una prueba de independencia de la ji al cuadrado $\left(\chi^{2}\right)$ para cinco encuestas efectuadas en tiempos diferentes: 1997, 2002, 2007,2012 y 2017.

\section{TABLA 3}

Pruebas de independencia de la relación entre intención de voto y valoración del PP y el PSOE. Coeficientes de la ji al cuadrado $\left(\chi^{2}\right)$

\begin{tabular}{llccccc}
\hline & \multicolumn{5}{c}{ Intención de voto } \\
\hline & & $\mathbf{1 9 9 7}$ & $\mathbf{2 0 0 2}$ & $\mathbf{2 0 0 7}$ & $\mathbf{2 0 1 2}$ & $\mathbf{2 0 1 7}$ \\
& & $\mathbf{( E 2 2 4 4 )}$ & $\mathbf{( E 2 4 5 4 )}$ & $(\mathbf{E 2 7 0 0 )}$ & $\mathbf{( E 2 9 4 1 )}$ & $\mathbf{( E 3 1 7 3 )}$ \\
\hline Valoración de gestión/ & PP & 728,798 & 905,290 & 754,737 & 1044,290 & 1091,858 \\
actuación & PSOE & 309,281 & 200,905 & 760,071 & 545,960 & 311,480 \\
\hline
\end{tabular}

Fuente: elaboración propia a partir de los microdatos de los estudios de abril de 1997, 2002, 2007, 2012 y 2017.

La conclusión es bastante evidente, en la medida que se observa para todos los años considerados que todos los coeficientes de la ji al cuadrado $\left(\chi^{2}\right)$ son significativos bilaterales al ,000. Las diferentes estrategias estadísticas adoptadas validan que las variables valoración de la gestión/actuación del PP y del PSOE están relacionadas con su intención de voto directa.

\section{DEBATE DE RESULTADOS}

Lo primero que se plantea es, en el caso español y considerando los dos partidos mayoritarios, lo difícil que es diferenciar empíricamente (desde el modelo del voto re- 
trospectivo) la evaluación de la actuación/gestión de los partidos de su imagen de partido; en línea con lo propuesto por Downs (1957), dado que la evaluación retrospectiva considera la actuación consistente en el tiempo de los partidos, en lo hecho y dicho en el pasado (en definitiva, la fiabilidad de los partidos). La evaluación de la actuación/ gestión de los partidos puede tener un recorrido temporal importante, que llega a convertirse en parte de la imagen del partido.

Hasta qué punto la percepción social de la capacidad de gestión o confianza en su actuación ha llegado a formar parte de la imagen de partido del PP y del PSOE es una pregunta que surge de considerar la evolución de la opinión pública. Los dos partidos, si bien expresan cambios de nivel puntual o integración positiva en determinadas legislaturas, muestran una tendencia consistente de declive que es más ajustada a la persistencia y difusión (en este caso en el empeoramiento de su valoración) de una imagen de partido en la opinión pública española.

Cabe establecer, en ese sentido, una fuerte interacción entre la imagen de partidos disfuncionales (mala valoración de gestión o actuación del PP y PSOE) y la valoración retrospectiva de su gestión o actuación en las convocatorias electorales. Es precisamente dicha interacción (la mala valoración de la gestión y actuación del partido como característica integrante de la imagen de partido) la que llega a explicar la crisis del sistema de partidos que se revela tras las elecciones generales de 2015.

De acuerdo con los datos evaluados, este rasgo de sus imágenes de partido (del PP y del PSOE) referido a la desconfianza en sus capacidades de gestión/actuación han convergido hasta hacerse intercambiables. El valor del indicador así lo confirma, en su evolución y en los mínimos alcanzados.

Otro aspecto a señalar es la capacidad analítica de una consideración longitudinal de los procesos de voto. A diferencia de las conclusiones extraídas de forma coyuntural en cada elección, la consideración del voto como parte de un proceso permite detectar patrones significativos y, como consecuencia, situaciones o periodos excepcionales. En ese sentido, cabe destacar en España el efecto de los factores de largo, medio y corto plazo. Como largo y medio plazo, el modelo de voto retrospectivo parece tener una capacidad explicativa elevada para el periodo 1996 a 2017. En ese aspecto, una posible conclusión es que la evaluación de la actuación de los partidos, integrada en las imágenes de los partidos, traspasa legislaturas (con puntuales cambios de nivel en periodos estacionarios, posiblemente asociados a cambio de líderes, en especial en el caso del PSOE). Respecto al tema español, la valoración de la actuación/gestión de los dos partidos mayoritarios hasta 2015 traspasa y desborda legislaturas. La tendencia de declive es generalizada y permanente.

En ese contexto, destacan los impactos puntuales de 2004 y de la crisis de 2008, que introducen cambios de nivel en las series (voto o valoración), pero que muestran 
una escasa duración, retomando rápidamente la tendencia decreciente en su valoración.

El estudio de las series referidas a la valoración de la gestión/actuación tanto del Partido Popular como del Partido Socialista Obrero Español y sus series respectivas de intención de voto apoya con carácter global la teoría del voto retrospectivo, según el cual la intención de voto tiene en cuenta la evaluación por parte de los electorados de la capacidad de gestión/actuación de los partidos y estaría asociado a ella. En ambos partidos es la característica más general considerando el periodo temporal estimado.

El análisis del largo plazo permite otra observación. A medio plazo, la aprobación de la gestión del Gobierno parece confirmar la propuesta sobre el deterioro que puede causar gobernar (en especial en las segundas o terceras legislaturas); el denominado coste de gobernar o fatiga de la acción de gobierno. Así, considerado de forma aislada, corresponde con el declive del PP entre 2000 y 2004 o del PSOE entre 2008 y 2011. Sin embargo, cuando se valoran las dinámicas a largo plazo, se aprecia como en ambos partidos el declive de la confianza en su capacidad política es de largo recorrido y se mantiene más allá de los periodos de gobierno u oposición. De hecho, desde esta perspectiva longitudinal y en relación con la crisis del bipartidismo en España, se observa que la tendencia de descrédito en la capacidad de gestión/actuación de los dos partidos es de largo recorrido, ya que el PP inicia su crisis de confianza en el año 2000 y el PSOE en el 2004. Paradójicamente, en esas dos elecciones ganaron el Gobierno tanto el PP como el PSOE de manera respectiva.

Al mismo tiempo, es justo la coordinación entre la intención de voto y la valoración la que permite apreciar la excepcionalidad del apoyo electoral al Partido Popular en el periodo 2008 a 2011, donde el voto de castigo hacia el PSOE se acumula de forma progresiva, a pesar de la imagen negativa que mantiene el PP en el conjunto de la opinión pública española. En dicho periodo, un PP desprestigiado en la valoración pública recibe apoyo electoral a contracorriente (efecto de castigo al PSOE).

En el caso del Partido Popular, existen segmentos electorales muy ideologizados que parecen reaccionar dándole apoyo en contextos y circunstancias de opinión pública nada favorables (en un entorno de profunda crisis económica y de deterioro de la acción de gobierno socialista). Es el carácter público de este apoyo, expresado mediante la intención de voto, lo que contradiciendo la tradicional interpretación de la ocultación del voto de derechas en España (basada en la teoría de la espiral del silencio formulada en los años 70 por Elisabeth Noelle-Neumann) señala la excepcionalidad del periodo.

Finalmente, la validación de las pautas detectadas a nivel agregado (macro) mediante análisis de patrones de respuesta individuales (micro) confirma la conexión entre ambos fenómenos políticos. La intención de voto al PP o al PSOE está asociada de manera significativa a la valoración que los votantes efectúan de su actuación/gestión. 
Queda por determinar el impacto de liderazgo en los periodos que muestran cambios de nivel, particularmente en el caso de la valoración del Partido Socialista Obrero Español, si bien dicho efecto parece actuar de un modo bastante moderado, subsumido en la tendencia general que muestra el proceso.

\section{BIBLIOGRAFÍA}

Abramowitz, A. I. (2008). «Forecasting the 2008 presidential election with the time-for-change model». Political Science and Politics, 41, 691-696.

Achen, Christopher H. (1992). «Social Psychology, Demographic Variables, and Linear Regression: Breaking the Iron Triangle in Voting Research». Political Behavior, 14:195-212.

Alaminos, Antonio y Alaminos-Fernández, Paloma (2017). «La potencia prospectiva del voto retrospectivo en España». Sociologiados, n. ${ }^{\circ}$ 2, vol. 1.

Alaminos, Antonio y Penalva, Clemente (2010). «Los medios de comunicación y el cambio político en España (1991-2000)». Sistema. Revista de Ciencias Sociales, (217) 19-40.

Alaminos, Antonio (2012). «Missing mixed mode: elemental structures». OBETS: Revista de Ciencias Sociales. Número 7. Páginas 327-333.

Alaminos, Antonio y Penalva, Clemente (2013). «España de los impactos de la crisis a las movilizaciones de protesta». Ecuador Debate. Agosto. Pág. 93-118.

Alaminos, Antonio (2015). «Forecasting elections with high volatility». Italian Journal of Applied Statistics. 25 (2), 165-184.

Alaminos, Antonio et al. (2015). Análisis multivariante para las Ciencias Sociales I. Índices de distancia, conglomerados y análisis factorial. Cuenca (Ecuador): PYDLOS Ediciones.

Alaminos, Antonio (1996). «Las predicciones electorales de las elecciones generales de 1996 en España». En VVAA Elecciones Generales 1996 y medios de comunicación en la región de Murcia. Murcia: Fundación Instituto de la Comunicación de Murcia. Alaminos, Antonio (1994). «Predicciones electorales en España» en Alaminos et al., Future Days. Alicante: Fundación Cultural CAM.

Alaminos, Antonio (1991). Teoría y práctica de la encuesta. Madrid: CEDEAL. Almond, Gabriel y Verba, Sidney (1965). The Civic Culture. Boston: Little, Brown. Alt, James E. (1984). «Dealignment and the Dynamics of Partisanship in Britain». En Dalton, Russel et al., Electoral Change in Advanced Industrial Societies: Realignment or Dealignment? Princeton: Princeton University Press. 
Alvarez, R. M. (1997). Information and Elections. Ann Arbor: University of Michigan Press.

Arceneaux, K. (2006). «Do Campaigns Help Voters Learn? A Cross-National Analysis», British Journal of Political Science, 36, 159-173.

Bartels, L. M. y Zaller, J. (2001). «Presidential Vote Models: A Recount», Political Science \& Politics, 34, 9-20.

Belknap, George y Campbell, Angus (1952). «Political Party Identification and Attitudes Toward Foreign Policy». Public Opinion Quarterly 15:601-23.

Biemer, P. P. (2010). «Overview of Design Issues: Total Survey Error» en P. V. Marsden y J. D. Wright eds. Handbook of Survey Research. Bingley: Emerald Group Publishing, pp. 27-57.

Brewer, Mark D. (2009). Party Images in the American Electorate. New York: Routledge. Brown, L. B. y Chappell, H. W. Jr. (1999). «Forecasting Presidential Elections Using History and Polls». International Journal of Forecasting, 15, 127-135.

Budge, Ian.; Crewe, Ivor y Farlie Dennis, eds. (1976). Party Identification and Beyond: Representations of Voting and Party Competition. New York: John Wiley \& Sons.

Campbell et al. (2010). «The Theory of Conditional Retrospective Voting: Does the Presidential Record Matter Less in Open-Seat Elections», Journal of Politics 72, 4 (2010): 1083-95.

Campbell, J. E. (2008). «The trial-heat forecast of the 2008 presidential vote: Performance and value considerations in an open-seat election». Political Science and Politics, 41, 697-702.

Campbell, J. E. (1996). «Polls and Votes: The Trial-Heat Presidential Election Forecasting Model, Certainty, and Political Campaigns», American Politics Research, 24, 408-433.

Campbell, J. y Garand, J. C. (2000). Before the vote. Forecasting American national elections. Thousand Oaks, CA: Sage Publications.

Campbell, J.E.; Cherry, L. L. y Wink, K. A. (1992), «The Convention Bump», American Politics Research, 20, 287-307.

Campbell, J. E. y Wink, K. A. (1990). «Trial-Heat Forecasts of the Presidential Vote», American Politics Research, 18, 251-269.

Campbell, Angus et al. (1966). Elections and the Political Order. New York: John Wiley and Sons.

Campbell, A.; Converse, P. E.; Miller, W. E.;, y Stokes, D. E. (1960). The American voter. New York: Wiley.

Campbell, Angus, Gerald Gurin y Warren E. Miller. (1954). The Voter Decides. Evanston, IL: Row Peterson. 
Clarke, Harold D., David Sanders, Marianne C. Stewart y Paul F. Whiteley. 2004. Political Choice in Britain. Oxford: Oxford University Press.

Clarke, Harold D., Stewart, Marianne y Whiteley, Paul. (1997a). «Tory Trends: Party Identification and the Dynamics of Conservative Support Since 1992». British Journal of Political Science 27:299-331.

Clarke, Harold D., Stewart, Marianne y Whiteley, Paul. (1997b). «New Models for New Labour: The Political Economy of Labour Party Support, January 1992-April 1997». American Political Science Review 92 (1998):559-76.

Cohen, Jeffrey E. (2015). Presidential Leadership in Public Opinion. Causes and consequences. New York: Cambridge University Press.

Converse, Philip E. (1976). The Dynamics of Party Support: Cohort-Analyzing Party Identification. Beverly Hills: Sage Publications.

Converse, Philip E. (1969). «Of Time and Partisan Stability», Comparative Political Studies 2:139-72.

Coser, Lewis (1956). The Functions of Social Conflict. New York: The Free Press, 1956.

Crespi, I. (1988). Pre-Election Polling: Sources of Accuracy and Error. New York: Russell Sage.

Dalton, Russel (2016). Party identification and its implication. Oxford Research Encyclopedia of Politics. Online Publication Date: May 2016. DOI: 10.1093/acrefore/9780190228637.013.72.

Downs (1957). An economic theory of democracy. New York: Harper and Row.

Duch, R. M. y Stevenson, R. T. (2008). The Economic Vote: How Political and Economic Institutions Condition Election Results, Cambridge: Cambridge University Press.

Easton, David (1975). «A Re-Assessment of the Concept of Political Support», British Journal of Political Science, 5. Pág: 435-57.

Erickson, R. S. y Wlezien, C. (2008). «Leading economic indicators, the polls, and the presidential vote». Political Science and Politics, 41, 703-708.

Erikson, Robert S.; MacKuen, Michael; Stimson, James. (2002). The Macro Polity. New York: Cambridge University Press.

Erikson, R. S. y Wlezien, C. (1999). «Presidential Polls as a Time Series: The Case of 1996», Public Opinion Quarterly, 63, 163-177.

Fair, R. C. (2009). «Presidential and Congressional Vote-Share Equations», American Journal of Political Science, 53, 55-72.

Falter, J. W.; Rattinger, H. (1982). «Parties, candidates and issues in the German federal election of 1980: An appraisal of normal vote analysis». Electoral Studies, 1, 65-94.

Fiorina, M. (1981). Retrospective voting in American national elections. New Haven: Yale University Press. 
Fleury, Christopher J. y Lewis-Beck, Michael S. (1993). «Anchoring the French Voter: Ideology versus Party», Journal of Politics 44:1100-09.

Francés, F. et al. (2014) El proceso de medición de la realidad social: La investigación a través de encuestas. Cuenca (Ec): PYDLOS.

Franklin, Charles H. (1984). «Issue Preferences, Socialization, and the Evolution of Party Identification», American Journal of Political Science 28: 459-78.

Franklin, Charles H. y Jackson, John E. (1983). «The Dynamics of Party Identification», American Political Science Review. 77: 957-73.

Gelman, A. y King, G. (1993). «Why Are American Presidential Election Campaign Polls So Variable When Votes Are So Predictable?», British Journal of Political Science, 23, 409-451.

González Rodríguez, Juan Jesús y Bouza Álvarez, Fermín (2009). Las razones del voto en la España democrática, 1977-2008. Madrid: Catarata.

Green, Donald P., Palmquist, Bradley y Schickler, Eric. (2002). Partisan Hearts and Minds. New Haven \& London: Yale University Press.

Groves, R. M. (1989). Survey Errors and Survey Costs. New York: Wiley.

Hillygus, D. S. y Jackman, S. (2003). «Voter Decision Making in Election 2000: Campaign Effects, Partisan Activation, and the Clinton Legacy», American Journal of Political Science, 47, 583-596.

Holbrook, T. M. (2008). «Incumbency, national conditions, and the 2008 presidential election». Political Science and Politics, 41, 709-712.

Holbrook, T. M. (1996). Do Campaigns Matter? Thousand Oaks, California: Sage.

Jackman, S. (2005). «Pooling the Polls Over an Election Campaign», Australian Journal of Political Science, 40, 499-517.

Jennings, M. Kent y Niemi, Richard. (1974). The Political Character of Adolescence: The Influence of Families and Schools. Princeton: Princeton University Press.

Kinder, D. R. y Kiewiet, D. R. (1991). «Sociotropic Politics: The American Case», British Journal of Political Science, 11, 129-161.

Key, V. O. (1966). The Responsible Electorate. Rationality in Presidential Voting 19361960. Harvard: Harvard University Press.

Key, V. O. (1964). Politics, parties and pressure groups. New York: Thomas Y. Crowell. Kramer, G. (1971). «Short-term fluctuations in U. S. voting behavior, 1896-1964». American Political Science Review, 65, 131-143.

Lewis-Beck, M. S. y Tien, C. (2008). «The job of the president and the jobs model forecast: Obama for '08?», Political Science and Politics, 41, 687-690.

Lewis-Beck, M. S. y Rice, T. W. (1992). Forecasting elections. Washington DC: CQ Press. 
Lewis-Beck, M. S., Jacoby, W. G., Norpoth, H. y Weisberg, H. F. (2008). The American voter revisited. Ann Arbor: University of Michigan Press.

McDermott, M. L. y Frankovic, K. A. (2003). «Review: Horserace Polling and Survey Method Effects: An Analysis of the 2000 Campaign», Public Opinion Quarterly, 67, 244-264.

Molto, Ezequiel (2013). Entrevista a Antonio Alaminos. Diario El País. Edición Comunidad Valenciana. 25 de mayo 2013.

Nadeau, R. y Lewis-Beck, M. S. (2001). «National Economic Voting in U.S. Presidential Elections», The Journal of Politics, 63, 159-181.

Norpoth, H. y Gschwend, T. (2010). «The chancellor model: Forecasting German elections». International Journal of Forecasting 26, 42-53.

Norpoth, H. (1978). «Party identification in West Germany: Tracing an elusive concept». Comparative Political Studies, 11, 36-61.

Panagopoulos, C. (2009). «Campaign Dynamics in Battleground and Non battleground States», Public Opinion Quarterly, 73, 119-129.

Panagopoulos, C. (2009c). «Polls and Elections: Preelection Poll Accuracy in the 2008 General Elections», Presidential Studies Quarterly, 39, 896-907.

Paldam, M. (1991). «How robust is the vote function? A study of seventeen nations over four decades». In H. Norpoth; Lewis-Beck M. y Lafay, J. D. (eds.), Economics and politics. The calculus of support. Ann Arbor: The University of Michigan Press. (pp. 9-31).

Parsons, T.; Shils, E. (1951). Toward a general theory of action. Cambridge: Harvard University Press.

Pickup, M. y Johnston, R. (2008). «Campaign Trial Heats as Election Forecasts: Measurement Error and Bias in 2004 Presidential Campaign Polls», International Journal of Forecasting, 24, 272-284.

Piqueras, José Antonio et al. (2011). El secuestro de la democracia: corrupción y dominación politica en la España actual. Madrid: Akal.

Romer, D., Kenski, K., Winneg, K., Adasiewicz, C. y Jamieson, K. H. (2006). Capturing Campaign Dynamics, 2000 and 2004: The National Annenberg Election Survey, Philadelphia: University of Pennsylvania Press.

Sanders, Arthur (1988). «The Meaning of Party Images». The Western Political Quarterly. Vol. 41, n. ${ }^{\circ} .3$, pp. 583-599.

Schickler, Eric y Green, Donald (1997). «The Stability of Party Identification in Western Democracies: Results From Eight Panel Surveys», Comparative Political Studies 30:450-83.

Shaw, D. R. (1999). «A Study of Presidential Campaign Event Effects From 1952 to 1992», Journal of Politics, 61, 387-422. 
Simmel, Georg (1908). Soziologie. Untersuchungen über die Formen der Vergesellschaftung, Leipzig: Duncker \& Humblot. Traducido en: Sociología: Estudios Sobre las Formas de Socialización. México: Fondo De Cultura Económica, 2015.

Stevenson, R. T. y Vavreck, L. (2000). «Does Campaign Length Matter? Testing for Cross-National Effects», British Journal of Political Science, 30, 217-235.

Stewart, Marianne C. y Clarke, Harold (1998). «The Dynamics of Party Identification in Federal Systems: the Canadian Case», American Journal of Political Science 42:97-116. Tezanos, José Félix y Luena, César (2017). Partidos políticos, democracia y cambio social. Madrid: Biblioteca Nueva.

Traugott, M. W. (2001). «Trends: Assessing Poll Performance in the 2000 Campaign», Public Opinion Quarterly, 65, 389-419.

Traugott, M. W. (2005). «The Accuracy of the National Preelection Polls in the 2004 Presidential Election», Public Opinion Quarterly, 69, 642-654.

Traugott, M. W. y Wlezien, C. (2009). «The Dynamics of Poll Performance During the 2008 Presidential Nomination Contest», Public Opinion Quarterly, 73, 866-894.

Trilling (1976). Party image and electoral behavior. New York: John Wiley and Sons.

Tufte, E. R. (1978). Political control of the economy. Princeton: Princeton University Press.

Vavreck, L. (2009). The Message Matters: The Economy and Presidential Campaigns, Princeton, NJ: Princeton University Press.

Wattenberg, Martin P. (2000). «The decline of party mobilization» en Dalton, Russel y Wattenberg, Martin P. (editors), Parties Without Partisans: Political Change in Advanced Industrial Democracies. Oxford: Oxford University Press.

Wattenberg, Martin P. (1986). The decline of American Political Parties, 1952-1984. Cambridge, Mass.: Harvard University Press.

Weisberg, H. F. (2005). The Total Survey Error Approach: A Guide to the New Science of Survey Research, Chicago, IL: University of Chicago Press.

Wlezien, C. y Erikson, R. S. (2002). «The Time line of Presidential Election Campaigns», The Journal of Politics, 64, 969-993.

Wlezien, C. y Erikson, R. S. (2002b). «Campaign Effects in Theory and Practice». American Politics Research. 29:419-437.

Wlezien, C. y Erikson, R. S. (1996). «Temporal Horizons and Presidential Election Forecasts», American Politics Research, 24, 492-505.

Zaller, J. (2002). «Assessing the Statistical Power of Election Studies to Detect Communication Effects in Political Campaigns», Electoral Studies 21:297-329.

Zaller, J. (1992). The Nature and Origins of Mass Opinion, Cambridge: Cambridge University Press. 